HARMS MG; DALLA PRIA M; REZENDE BLA; PRESTES AMC; DALAZOANA F. 2015. Influência da densidade de plantas e do uso de fungicida nas doenças foliares e na produtividade de cebola. Horticultura Brasileira 33: 203-207. DOI - http://dx.doi.org/10.1590/S0102-053620150000200011

\title{
Influência da densidade de plantas e do uso de fungicida nas doenças foliares e na produtividade de cebola
}

\author{
Mônica G Harmsi'; Maristella Dalla Pria'; ${ }^{1}$ Bráulio LA Rezende ${ }^{2}$; André MC Prestes ${ }^{1}$; Felipe Dalazoana ${ }^{1}$ \\ ${ }^{1}$ UEPG, Depto. Fitotecnia e Fitossanidade, Av. Carlos Cavalcanti 4748, 84030-900 Ponta Grossa-PR; monicaharms@bol.com.br; \\ mdallapria@uepg.br; andremanossop@hotmail.com; felipedalazoana@ibest.com.br; ${ }^{2}$ IFSULDEMINAS-Câmpus Muzambinho, Lab. \\ Olericultura, Estr. de Muzambinho km 35, s/n, Morro Preto, 37890-000 Muzambinho-MG; blrezende76@gmail.com; braulio.rezende@ \\ muz.ifsuldeminas.edu.br
}

\section{RESUMO}

Com o objetivo de avaliar a influência da densidade de plantas e aplicação de fungicida na ocorrência de doenças foliares e na produtividade de bulbos de cebola da cultivar Bola Precoce, em Ponta Grossa-PR, foram conduzidos experimentos nas safras 2010 e 2011 . O delineamento utilizado foi blocos ao acaso em parcelas subdivididas, onde as parcelas constituíram a presença ou ausência de fungicida (metiram + piraclostrobina $-2,5 \mathrm{~kg} /$ ha do p.c.) e as subparcelas constituíram as densidades de plantas, sendo 12 plantas/m(363.636 plantas/ ha), 14 plantas $/ \mathrm{m}$ (424.242 plantas/ha), 16 plantas/m(484.848 plantas/ ha), 18 plantas $/ \mathrm{m}$ (545.454 plantas/ha), 20 plantas $/ \mathrm{m}$ (606.060 plantas/ ha) e 22 plantas $/ \mathrm{m}$ (666.666 plantas/ha). O tratamento fungicida foi aplicado aos 89, 100 e 110 dias após o transplante (DAT). Avaliou-se a severidade do míldio (Peronospora destructor) e da mancha púrpura (Alternaria porri) aos 90, 97, 104 e 111 DAT. A colheita dos bulbos foi realizada aos 180 DAT. Nos dois anos de experimento não foram observadas interações entre densidade de plantas e utilização do fungicida para a severidade e para a área abaixo da curva do progresso da doença (AACPD) do míldio e da mancha púrpura. Para severidade de doenças, não houve diferença significativa entre as densidades estudadas, independentemente da pulverização ou não do fungicida, assim como para a massa e o diâmetro médio de bulbos. Foi observado um aumento linear da produtividade total e do número de bulbos com o incremento da densidade de plantas. Na safra de 2011, observou-se um aumento linear de bulbos pertencentes à classe 1 com o aumento da densidade de plantas, demonstrando que plantios mais adensados tendem a produzir bulbos de tamanho reduzido.

Palavras-chave: Allium cepa, Alternaria porri, Peronospora destructor, míldio, mancha púrpura, população de plantas.

\section{ABSTRACT}

Effects of plant density and fungicide application on foliar diseases and onion yield

The effects of plant density and fungicide application on the severity of foliar diseases and onion yield ('Bola Precoce') were studied in 2010 and 2011, in Ponta Grossa, Paraná state, Brazil. The experiments were carried out in the field in randomized block design in a split plot. A fungicide (metiram + pyraclostrobin, $2.5 \mathrm{~kg} / \mathrm{ha}$ of c.p.) was either applied or not applied to the plotsat 89, 100 and 110 days after seedling transplantation (DAT). The subplots consisted of the following plant densities: 12 plants $/ \mathrm{m}, 14$ plants $/ \mathrm{m}, 16$ plants $/ \mathrm{m}$, 18 plants $/ \mathrm{m}, 20$ plants $/ \mathrm{m}$, and 22 plants $/ \mathrm{m}$. The severity of downy mildew (Peronospora destructor) and purple blotch (Alternaria porri) were assessed at 90, 97, 104, and 111 DAT. Harvesting of bulbs was performed at 180 DAT. No relationships were observed between plant density and fungicide use and the severity and area under the disease progress curve for mildew and purple blotch. In addition, no significant differences among disease severities and plant densities, regardless of fungicide application or the average mass and diameter of the bulbs. In 2011, a linear increase in Class 1 bulbs with increasing plant density was observed, demonstrating that denser planting leads to smaller bulbs.

Keywords: Allium cepa, Alternaria porri, Peronospora destructor, downy mildew, purple blotch, plant population.

(Recebido para publicação em 1 de outubro de 2013; aceito em 23 de setembro de 2014) (Received on October 1, 2013; accepted on September 23, 2014)

\begin{abstract}
A cebola (Allium cepa) é a segunda hortaliça em importância mundial, superada apenas pelo tomate (Song et al., 2007). A China é o maior produtor mundial de cebola, com um volume de 24,7 milhões de toneladas, enquanto o Brasil ocupa a décima posição, com um volume de 1,52 milhão de toneladas (FAO, 2013).

Baseados na necessidade de produção de bulbos médios, pertencentes à
\end{abstract}

classe 3 (51 a 60 mm de diâmetro), os produtores têm buscado novas distribuições espaciais de plantas, objetivando colheita de bulbos de acordo com o tamanho exigido pelo consumidor. A competição por água, luz e nutrientes faz com que o tamanho do bulbo e a produtividade total variem de acordo com a população de plantas na área (Resende \& Costa, 2005b).

A população de plantas ideal a ser empregada é aquela suficiente para atingir o índice de área foliar ótimo a fim de interceptar o máximo de radiação solar útil à fotossíntese e ao mesmo tempo maximizar a fração da matéria seca alocada às partes vegetativas e produtivas (Hao \& Papadopoulus, 1999), diminuindo as pressões de competição interplantas.

Santos et al. (2000) estudaram a cultivar Texas Grano em diferentes 
espaçamentos entre plantas na linha (5; 10 e $15 \mathrm{~cm}$ ) e $30 \mathrm{~cm}$ nas entrelinhas. Os autores verificaram redução na massa do bulbo quando houve a redução no espaçamento, mostrando uma grande influência sobre a produtividade. $\mathrm{O}$ espaçamento de $5 \mathrm{~cm}$ entre plantas na linha proporcionou maior produtividade (40,3 t/ha), com massa média de 53,1 $\mathrm{g}$ por bulbo. Embora a massa do bulbo no espaçamento de $15 \mathrm{~cm}$ entre plantas tenha proporcionado bulbos maiores $(83,4 \mathrm{~g})$, a produtividade dos mesmos teve redução de 19,35\% em relação aos tratamentos mais adensados, que, segundo os autores, se deve à redução de $50 \%$ na população de plantas na mesma área cultivada.

A população de plantas também tem influência sobre o desenvolvimento de doenças, pois tem relação com a disseminação das unidades infectivas do patógeno e a formação de microclima na cultura, afetando a passagem do vento, o sombreamento do solo e alterando a umidade relativa do ar. Assim, o adensamento de plantas influencia diretamente o período de molhamento foliar, a luminosidade e a umidade relativa do ar, que constituem fatores climáticos importantes para o desenvolvimento de várias doenças da cebola, como o míldio (Peronospora destructor) e a mancha púrpura (Alternaria porri) (Boff et al., 1998).

Estudando a influência de três espaçamentos $(10 \times 20 \mathrm{~cm}, 8 \times 40 \mathrm{~cm} \mathrm{e}$ $10 \times 50 \mathrm{~cm}$ ) na ocorrência de doenças foliares na cultura da cebola, variedade Crioula, Boff et al. (1998) verificaram que o menor espaçamento apresentou maior intensidade de doenças foliares que os demais. Independentemente do espaçamento utilizado, a pulverização com fungicida reduziu a severidade média das doenças, embora os autores não tenham encontrado diferença na incidência da mancha púrpura e da queima-acizentada (Botrytis squamosa) entre parcelas tratadas e não tratadas com os fungicidas vinclozolin, metalaxil-mancozeb ou iprodione.

O presente trabalho teve por objetivo avaliar a influência da densidade de plantas e o uso de fungicida (metiram + piraclostrobina) na ocorrência de míldio e mancha púrpura e nas características produtivas da cultivar Bola Precoce.

\section{MATERIAL E MÉTODOS}

Foram conduzidos dois experimentos nas safras de 2010 e 2011, no município de Ponta Grossa-PR (2513'S, $50^{\circ} 03^{\prime} \mathrm{O}, 900 \mathrm{~m}$ de altitude). O solo da área cultivada é classificado como CAMBISSOLO HÁPLICO Tb Distrófico típico, textura argilosa (Embrapa, 2006).

O delineamento experimental utilizado foi de blocos ao acaso com quatro repetições. Os tratamentos foram arranjados em parcelas subdivididas, sendo as parcelas caracterizadas pela ausência ou presença do tratamento com fungicida (metiram + piraclostrobina, $2,5 \mathrm{~kg} /$ ha do p.c.), registrado para a cultura da cebola e recomendado para o controle de míldio e mancha púrpura; e as densidades de plantas constituíram as subparcelas. As densidades de plantas utilizadas foram 12 plantas/m (363.636 plantas/ha), 14 plantas/m (424.242 plantas/ha), 16 plantas/m (484.848 plantas/ ha), 18 plantas/m (545.454 plantas/ha), 20 plantas $/ \mathrm{m}$ (606.060 plantas/ha) e 22 plantas/m (666.666 plantas/ha).

No ano de 2010, a semeadura manual foi realizada no dia 26/06/10, em fileiras espaçadas de $33 \mathrm{~cm}$, totalizando seis linhas por subparcela $(1,65 \times 4,0 \mathrm{~m})$.

A emergência ocorreu 17 dias após a semeadura (DAS). Para a adubação de base, utilizou-se o fertilizante NPK da fórmula 5-25-25 na dosagem de 300 $\mathrm{kg} / \mathrm{ha}$. A adubação em cobertura (36-0012) foi realizada aos 62 e 82 dias após a emergência (DAE). O controle de plantas daninhas foi realizado através de capina manual e da aplicação de herbicida (Ioxinil octanoato - 1,0 L/ha do p.c) aos 23 e 36 DAE. A aplicação de fungicida foi realizada aos 56 e 117 DAE. O monitoramento da ocorrência das doenças foi semanal até o surgimento dos primeiros sintomas. A primeira avaliação ocorreu aos 119 DAE e a segunda aos 137 DAE, determinando a porcentagem de tecido foliar atacado por míldio e mancha púrpura, em 16 plantas nas linhas centrais de cada parcela, utilizando-se a escala diagramática (Azevedo, 1997). A colheita dos bulbos da área útil da parcela, (2,97 $\mathrm{m}^{2}$ de plantas das linhas centrais) ocorreu quando $80 \%$ das plantas apresentavam o tombamento da parte aérea (estalo), aos 148 DAE. Os bulbos foram armazenados em galpão ventilado por 30 dias para a realização da cura.

$\mathrm{Na}$ safra de 2011, as mudas foram transplantadas no dia 06/07/11. Os tratos culturais foram semelhantes aos realizados no ano de 2010. A adubação em cobertura (36-00-12) foi realizada aos 54 e 80 DAT. A aplicação de herbicida (Ioxinil octanoato, 1,0 L/ha do p.c.) ocorreu aos 19 e 34 DAT. A primeira aplicação do fungicida foi realizada aos 89 DAT, quando constatada a ocorrência dos primeiros sintomas de míldio. Durante o ciclo da cultura, ainda foram feitas mais duas aplicações do mesmo fungicida aos 100 e 110 DAT. As avaliações da severidade do míldio e da mancha púrpura ocorreram aos 90, 97, 104 e 111 DAT. A colheita foi realizada aos 180 DAT (10/12/11).

Nos dois experimentos quantificou-se o número de bulbos $/ \mathrm{m}^{2}$, a massa e o diâmetro médio dos bulbos e a produtividade total. Com os dados obtidos nas avaliações de severidade, foi possível calcular a área abaixo da curva do progresso da doença (AACPD). Os dados obtidos foram submetidos à análise de variância pelo teste de $\mathrm{F}$, as médias de fungicidas quando significativas foram comparadas pelo teste de Tukey a 5\% de probabilidade e as densidades de plantas, quando significativas, foram submetidas à análise de regressão. Para análise, os dados expressos em porcentagem, foram transformados em arc sen $\operatorname{raiz}(\mathrm{x}+0,5) / 100$. As análises foram realizadas através do programa estatístico STAT (Sistemas para análises estatísticas, V. 2.0) (STAT, 2001).

\section{RESULTADOS E DISCUSSÃO}

Nos dois anos do experimento, não foi observada interação entre densidade de plantas e utilização do fungicida para a severidade e para a ACPD do míldio e da mancha púrpura, bem como para os tratamentos isoladamente.

A densidade de plantas tem maior influência onde o microclima está em condições ótimas ao desenvolvimento da doença, pois o adensamento de plantas pode propiciar microclima favorável ao desenvolvimento de patógenos, oferecendo maior probabilidade de contato das unidades infectivas sobre o hospedeiro. O período de molhamento 
Tabela 1. Severidade do míldio (Peronospora destructor) e da mancha púrpura (Alternaria porri) na ausência e presença de fungicida (metiram + piraclostrobina) em cebola (Allium сера) nos anos de 2010 e 2011 sseverity of downy mildew (Peronospora destructor) and purple blotch (Alternaria porri) in the absence or presence of the fungicide metiram + pyraclostrobin in onion (Allium cepa) in 2010 and 2011\}. Ponta Grossa, UEPG, 2010/2011.

\begin{tabular}{|c|c|c|c|c|c|c|}
\hline \multirow{3}{*}{ Fungicida } & \multicolumn{2}{|c|}{ Míldio } & \multicolumn{4}{|c|}{ Mancha púrpura } \\
\hline & \multirow{2}{*}{$\frac{2010}{119 \text { DAE }}$} & \multirow{2}{*}{$\frac{2011}{97 \text { DAT }}$} & \multirow{2}{*}{\multicolumn{2}{|c|}{$\frac{2010}{119 \text { DAE } 137 \text { DAE }}$}} & \multicolumn{2}{|c|}{2011} \\
\hline & & & & & 97 DAT & 104 DAT \\
\hline Sem & $9,39 \mathrm{~A}^{*}$ & $19,01 \mathrm{~A}$ & $6,86 \mathrm{~A}$ & $12,81 \mathrm{~A}$ & $21,44 \mathrm{~A}$ & $28,36 \mathrm{~A}$ \\
\hline Com & $7,87 \mathrm{~B}$ & $16,05 \mathrm{~B}$ & $6,05 \mathrm{~B}$ & $10,12 \mathrm{~B}$ & $20,01 \mathrm{~B}$ & $25,01 \mathrm{~B}$ \\
\hline CV (\%) & 8,29 & 11,19 & 2,87 & 15,79 & 6,64 & 7,28 \\
\hline
\end{tabular}

*Médias seguidas de mesma letra maiúscula na coluna não diferem entre si pelo teste de Tukey a 5\% de significância; *Dados originais de severidade; para análise os dados foram transformados em arc sen $\operatorname{raiz}(\mathrm{x}+0,5) / 100 ; \mathrm{DAE}=$ dias após a emergência; $\mathrm{DAT}=$ dias após o transplante (*means followed by the same capital letter in the column do not differ, according to the Tukey test $5 \%$; *original severity data; for the analysis, the data were transformed using arc sin square $\operatorname{root}(\mathrm{x}+0,5) / 100 ; \mathrm{DAE}=$ days after emergence; $\mathrm{DAT}=$ days after transplantation).

foliar é a variável climática mais importante no desenvolvimento de doenças foliares (Agrios, 2005), como o míldio e mancha púrpura. No clima da região onde foi realizado o experimento (Ponta Grossa-PR), observa-se aumento da temperatura de acordo com o avanço do ciclo da cultura, desfavorecendo a ocorrência de algumas doenças, como o míldio. Isto pode ser um dos fatores pelos quais não houve diferença signi- ficativa entre as densidades de plantas e a severidade de míldio nas avaliações realizadas, pois a faixa de temperatura ideal para o desenvolvimento da doença é de 10 a $15^{\circ} \mathrm{C}$.

Em relação à aplicação do fungicida (Tabela 1), foram encontradas diferenças $(p<0,05)$ entre os tratamentos com e sem aplicação para a $1^{\text {a }}$ avaliação do míldio (119 DAE) e para a $1^{\mathrm{a}}$ e $2^{\mathrm{a}}$ avaliações da mancha púrpura (119 e
137 DAE) na safra de 2010. Na safra de 2011, foram observadas diferenças $(\mathrm{p}<0,05)$ na $2^{\mathrm{a}}$ avaliação do míldio $(97$ DAT) e na $2^{\mathrm{a}}$ e $3^{\mathrm{a}}$ avaliação da mancha púrpura (realizadas respectivamente aos 97 e 104 DAT), onde a severidade destas doenças foi maior na ausência do fungicida. Estes resultados estão de acordo com os encontrados por Boff $e t$ al. (1998) que citam que, independentemente do espaçamento utilizado, a pulverização com fungicida (vinclozolin, metalaxil-mancozeb ou iprodione) reduziu a severidade média das doenças.

De acordo com os resultados obtidos nas avaliações realizadas para massa e diâmetro médio de bulbo, em ambas as safras, não se observou interação significativa entre densidade de plantas e utilização do fungicida, bem como para os tratamentos isoladamente.

Os resultados obtidos mostram que houve resposta linear para a produtividade total, tanto na presença quanto na ausência de fungicida, ou seja, a produtividade total aumentou linearmente com o aumento da densidade de plantas. $\mathrm{Na}$ safra de 2010, as maiores produtividades foram alcançadas na densidade de 20 plantas/m, tanto na presença quanto ausência de fungicida, sendo estes valores

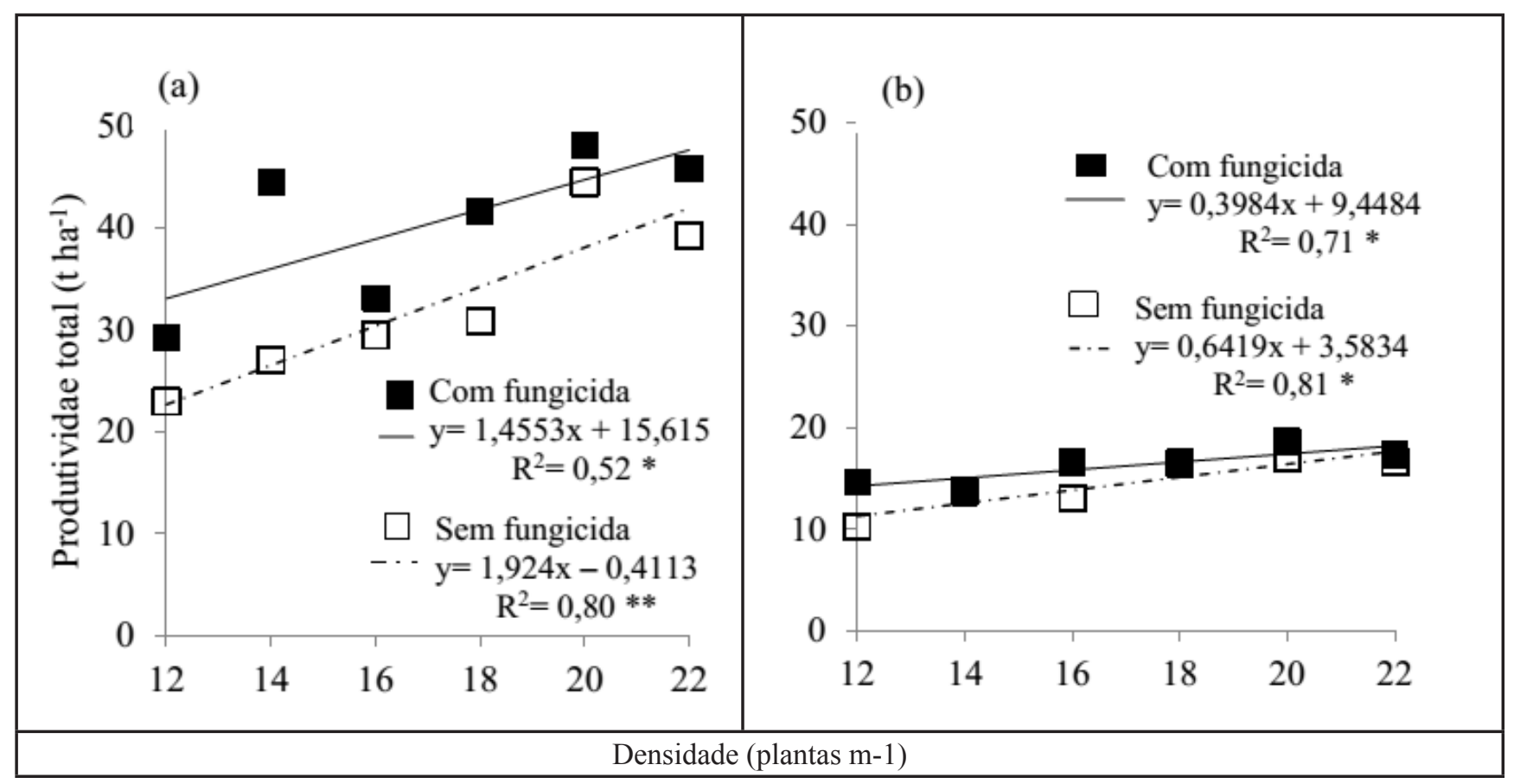

Figura 1. Produtividade total (t/ha) de bulbos cebola (A. серa) em diferentes densidades de plantas, na presença e ausência de fungicida (metiram + piraclostrobina) no ano de (a) 2010 e (b) 2011 ; * $\mathrm{e}^{* *=}$ significativo a $5 \%$ e $1 \%$, respectivamente [total yield ( $\mathrm{t} / \mathrm{ha}$ ) of onion bulbs (Allium cepa) at different plant densities and in the presence or absence of the fungicide metiram + pyraclostrobin in (a) 2010 and (b) 2011 ; *and**= significant at 5\% and 1\%, respectively]. Ponta Grossa, UEPG, 2010/2011. 


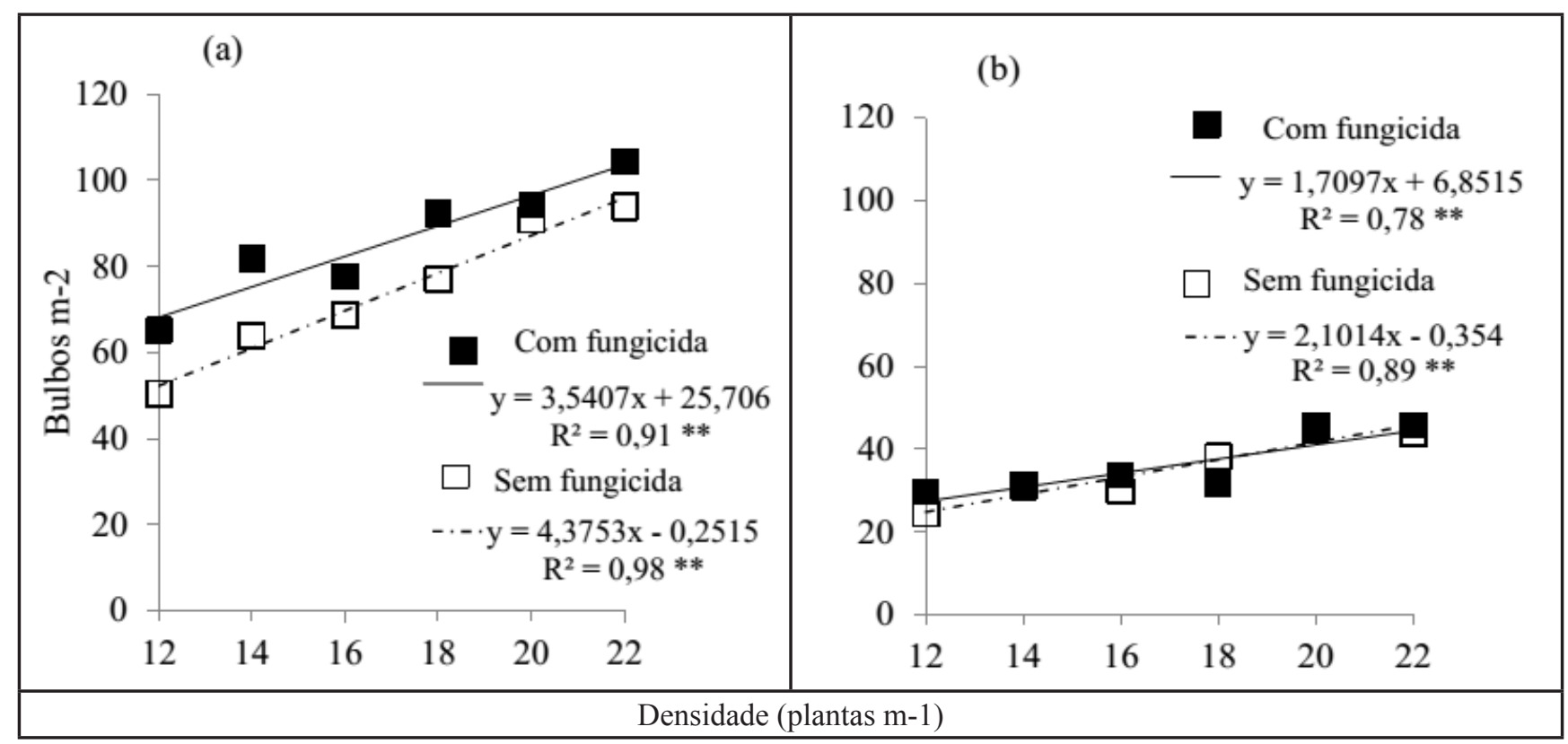

Figura 2. Número de bulbos de cebola (A. cepa) em diferentes densidades de plantas, na presença e ausência do fungicida metiram + piraclostrobina no ano de (a) 2010 e (b) $2011 ; *{ }^{* *}=$ significativo a $5 \%$ e $1 \%$, respectivamente [number of onion bulbs (Allium cepa) at different plant densities in the presence or absence of the fungicide metiram + pyraclostrobin in (a) 2010 and (b) 2011 ; *and**= significant at $5 \%$ and $1 \%$, respectively]. Ponta Grossa, UEPG, 2010/2011.

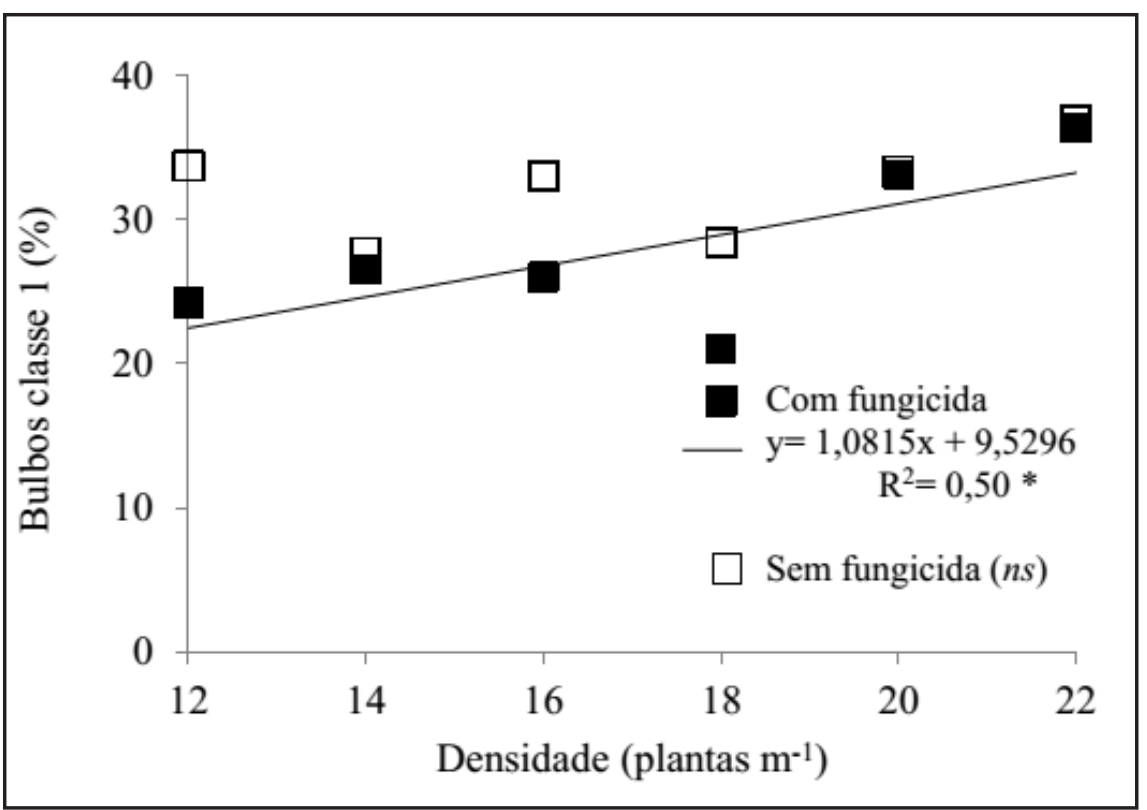

Figura 3. Bulbos de cebola cultivar Bola Precoce de classe 1 em diferentes densidades de plantas, na presença e ausência de fungicida (metiram + piraclostrobina); *= significativo a 5\% (class 1 onion bulbs of 'Bola Precoce' cultivar at different plant densities in the presence or absence of the fungicide metiram + pyraclostrobin; * significant at 5\%). Ponta Grossa, UEPG, 2010/2011.

de 47,63 e $41,92 \mathrm{t} / \mathrm{ha}$, respectivamente (Figura 1), com um aumento de 5,71 t/ ha com a aplicação de fungicida. Comportamento semelhante, na densidade de 22 plantas $/ \mathrm{m}$, foi observado na safra de 2011, sendo as produtividades máximas, na presença e ausência de fungicida, de 18,21 e $17,7 \mathrm{t} / \mathrm{ha}$, respectivamente (Fi- gura 1). Comparando as densidades de $12(14,22 \mathrm{t} / \mathrm{ha})$ e 22 plantas/m $(18,21 \mathrm{t} /$ ha), houve aumento de $28 \%$ na produtividade, quando o fungicida foi aplicado. Estes resultados mostram a importância da determinação da densidade de plantas a ser utilizada na obtenção de produtividades desejáveis.
Os resultados encontrados no presente trabalho são discordantes dos de May (2006), pois demonstram que a densidade de plantas influenciou a produtividade $(\mathrm{p}<0,05)$ e que a massa fresca dos bulbos não diferiu estatisticamente entre as diferentes densidades de plantas.

Kanton et al. (2002) verificaram que a menor população de plantas estudada em sistema de produção de cebola transplantada $\left(37,04\right.$ plantas $\left./ \mathrm{m}^{2}\right)$ produziu bulbos de maior massa comparativamente às plantas conduzidas na população de 156,25 plantas $/ \mathrm{m}^{2}$. Houve redução significativa da produtividade, passando de 37,95 t/ha de bulbos na maior população para $22,27 \mathrm{t} / \mathrm{ha}$ de bulbos na menor. Resultados semelhantes foram encontrados no presente trabalho, onde a produtividade passou de $33,07 \mathrm{t} /$ ha na população de 36,3 plantas $/ \mathrm{m}^{2}$ (12 plantas $/ \mathrm{m}$ ) para $47,63 \mathrm{t} / \mathrm{ha}$ na população de 66,6 plantas $/ \mathrm{m}^{2}$ (22 plantas $/ \mathrm{m}$ ) no ano de 2010.

Em relação ao número de bulbos produzidos, o incremento foi linear com o aumento da densidade de plantas nas duas safras. Para a densidade de 22 plantas $/ \mathrm{m}$, no primeiro ano, o número de bulbos produzidos com a aplicação do fungicida foi de 103,6 bulbos $/ \mathrm{m}^{2}$, enquanto na ausência do fungicida, fo- 
ram produzidos 96 bulbos $/ \mathrm{m}^{2}$ (Figura 2). Este resultado era esperado, pois maiores populações tendem a produzir maior número de bulbos, no entanto, com um tamanho reduzido. No segundo ano, para a densidade de 22 plantas $/ \mathrm{m}$, com a aplicação do fungicida, a produção foi de 44,46 bulbos $/ \mathrm{m}^{2}$, enquanto que na ausência do fungicida, a produção foi de 45,88 bulbos $/ \mathrm{m}^{2}$. A diferença entre o número de bulbos produzidos nas duas safras influenciou a produtividade, e a quantidade inferior de bulbos produzidos na safra de 2011 foi responsável pela menor produtividade em comparação à safra de 2010.

As pressões de competição interplantas exercidas pela população de plantas afetam de modo marcante o desenvolvimento da cebola. Resultados obtidos por Resende \& Costa (2005a) evidenciaram uma relação inversa entre a densidade de plantio e o tamanho do bulbo. De forma geral, altas densidades produzem maior número de bulbos por área, mas com menor massa fresca e consequentemente, menor produtividade comercial. Quando a densidade de plantas aumenta por unidade de área atinge-se um ponto no qual as plantas competem por fatores essenciais de crescimento, como nutrientes, luz e água.

A classificação dos bulbos segundo o tamanho (Brasil, 1995), é um indicador da qualidade de produção alcançada. Para a classificação dos bulbos, não foi observada interação significativa entre densidade de plantas e a aplicação de fungicida, sendo os dados analisados isoladamente. Em 2010, não houve diferença entre as densidades de plantas para todas as classes de bulbos. Em 2011, as porcentagens de bulbos encontradas nas classes $0(<15 \mathrm{~mm}), 2$ (36 a $50 \mathrm{~mm}), 3$ (51 a $60 \mathrm{~mm})$ e $3 \mathrm{C}$ (61 a $70 \mathrm{~mm})$ não diferiram estatisticamente entre as densidades de plantas. Nesse ano, não foram obtidos bulbos pertencentes à classe 4 (>70 mm). Para bulbos pertencentes à classe 1, foi verificada diferença significativa entre as densidades (Figura 3). Houve resposta linear, a porcentagem de bulbos pertencentes à classe 1 (15 a $35 \mathrm{~mm}$ ) aumentou com o incremento da densidade de plantas, quando aplicado o fungicida.

A menor porcentagem $(22,51 \%)$ de bulbos pertencentes à classe 1 foi pro- duzida na densidade de 12 plantas/m, enquanto que a maior porcentagem $(33,32 \%)$ foi produzida na densidade de 22 plantas/m. Este resultado confirma que plantios mais adensados tendem a produzir bulbos de tamanho reduzido, concordando com Resende \& Costa (2006) que afirmam que em populações menores a produtividade é menor e se produz alta porcentagem de bulbos médios e grandes; já em cultivos com densidades maiores que a ótima, se tem bulbos pequenos, desuniformes e de qualidade comercial inferior. Rumpel \& Felczynski (2000) também verificaram que a produção de bulbos grandes é gradativamente decrescente com o aumento da população de plantas. Os autores constataram que os maiores bulbos foram produzidos nas populações de $20 \mathrm{a}$ 40 plantas $/ \mathrm{m}^{2}$, enquanto que os menores bulbos foram alcançados na população de 140 plantas $/ \mathrm{m}^{2}$.

Diferenças não foram observadas em relação aos bulbos pertencentes à classe 2 entre as densidades de plantio, sendo que bulbos da classe 2 também são considerados bulbos de tamanho pequeno. Foram encontrados valores altos (média de $50,79 \%$ ) de bulbos na classe 2 ( $>35$ a $50 \mathrm{~mm}$ ), independentemente da densidade de plantio, discordando de Dawar et al. (2007), onde os autores encontraram o maior peso total de bulbos pequenos $(738,11 \mathrm{~g})$ na maior população de plantas utilizadas ( 80 plantas $/ \mathrm{m}^{2}$ ), enquanto o menor peso total de bulbos pequenos $(181,78 \mathrm{~g})$ foi alcançado na densidade de 40 plantas $/ \mathrm{m}^{2}$.

A produtividade e o número de bulbos de cebola aumentaram linearmente com o aumento da densidade de plantas. A aplicação do fungicida não influenciou a massa, o diâmetro e número de bulbos produzidos nas duas safras. As diferentes densidades de plantas não influenciaram a severidade das doenças nas avaliações realizadas. Na safra de 2010, a aplicação de fungicida reduziu a severidade da mancha púrpura e do míldio nas avaliações realizadas aos 119 e 137 DAE, e 119 DAE, respectivamente. Na safra de 2011, a redução de severidade da mancha púrpura e do míldio com a aplicação do fungicida ocorreu nas avaliações realizadas aos 97 e 104 DAT, e 97 DAT respectivamente.

\section{REFERÊNCIAS}

AGRIOS GN. 2005. Plant Pathology. 5 ed. New York: Academic Press, 922p.

AZEVEDO LAS. 1997. Manual de quantificação de doenças de plantas. Ed. do autor. 114p.

BOFF P; STUKER H; GONÇALVES PAS. 1998. Influência da densidade de plantas na ocorrência de doenças foliares e produção de bulbos de cebola. Fitopatologia Brasileira 23: 448-452.

BRASIL. 1995. MARA. Portaria n.529 de 18 agosto. Diário Oficial da República Federativa do Brasil, 1 setembro 1995, Seção1, p.13513.

DAWAR NM; WAZIR FK; DAWAR MD; DAWAR SH. 2007. Effect of planting density on growth and yield of onion varieties under climatic conditions of Peshawar. Sarhad Journal of Agriculture 24: 911-918.

EMBRAPA. 2006. Sistema brasileiro de classificação de solos.

FAO. 2013, 08 de agosto. Agricultural production, primary crops. Disponível em: http://www. fao.org.

HAO X; PAPADOPOULOS AP. 1999. Effects of supplemental lighting and cover materials on growth, photosynthesis, biomass partitioning, early yield and quality of greenhouse cucumber. Scientia Horticulturae 80: 1-18.

KANTON RAL; ABBEY L; HILLA RG; TABIL MA; JAN ND. 2002. Density affects plant development and yield of bulb onion (Allium cepa) in northern Ghana. Journal of Vegetable Crop Production 8: 15-25.

MAY A. 2006. Desempenho de híbridos de cebola em função da população de plantas e fertilização nitrogenada e potássica. Jaboticabal: UNESP. 157p. (Tese doutorado).

RESENDE GM; COSTA ND. $2005 \mathrm{a}$. Características produtivas e conservação póscolheita de cebola em diferentes espaçamentos de plantio. Horticultura Brasileira 23: 707-711.

RESENDE GM; COSTA ND. 2005b. Produtividade e armazenamento de cebola, cv. Alfa Tropical, cultivada em diferentes espaçamentos. Horticultura Brasileira 23: 1010-1014.

RESENDE GM; COSTA ND. 2006. Produtividade e massa fresca de bulbos de cebola sob densidades de plantio no Vale do São Francisco. Horticultura Brasileira 24: 228-232.

RUMPEL J; FELCZYNSKI K. 2000. Effect of plant density on yield and bulb size of direct sown onions. Acta Horticulturae 533: 179-186.

SANTOS HS; TANAKA MT; WATANABE SH; ARANTES PAZ; IVONE TT. 2000. Produção de cebola em função de tamanho de muda e espaçamento. Horticultura Brasileira 18:556557 (Suplemento).

SONG SI; CHEONG JJ; CHOI YD. 2007. Onion, garlic and related species. Biotechnology in Agriculture and Forestry 59: 415-433.

STAT - Sistema de análises estatísticas. 2001. Jaboticabal: DCE/FCAV/UNESP(CD-Rom). 